\title{
Decision Support System on Government Emergency Management for Urban Emergency
}

\author{
Zhe $\mathrm{Li}^{1, \mathrm{a}}$, Xiang Teng ${ }^{2, \mathrm{~b}}$, Jiahui Wang ${ }^{3, \mathrm{c}}$ \\ ${ }^{1}$ College of International Exchange, Bohai University, Jinzhou, 121013, China \\ ${ }^{2}$ Basic Teaching and Research Institute, Bohai University, Jinzhou, 121013, China \\ ${ }^{3}$ College of Information Science and Technology, Bohai University, Jinzhou, 121013, China \\ a503412508@qq.com, byyq8369@163.com, '624351108@qq.com
}

Keywords: urban management; emergency; emergency management; government; decision support system; DSS

\begin{abstract}
Improve the ability of urban rapid response and anti-risk to sudden events, provide more efficient emergency rescue service for urban residents, just to be the problem to solve faced by city managers. In this paper, we study the decision support system for the government emergency decision support. First of all, research by the interaction of language and problems systems, as well as database, model base, method base and knowledge base management system such as system structure; Then the city emergency government emergency decision support system, and the main functions are described; Finally, the case-based reasoning technology, and explains the city emergency contingency plans of government emergency management process of reasoning. The research results in this paper, for emergency management ability of the urban emergency government provides a new method and train of thought.
\end{abstract}

\section{Introduction}

Emergency refers to a sudden, cause or may cause serious social harm, need to take emergency measures to deal with natural disasters, accidents disasters, public health and social security events. Broadly, unexpected events can be understood as suddenly happen: the first layer of meaning is the event occurrence, development of fast, unexpectedly; The second is the meaning of events is difficult to deal with, unconventional methods must be taken to deal with. The modern city is a highly complex, multi-functional, comprehensive organisms, is the political, economic and cultural center, within a certain area plays a industrial production base, circulation of commodities hub, financial center, information center, science and technology culture and education center, and opening up to the window and other functions, at the national and regional economic development and social advancement plays a leading role. But people enjoying the development achievement, at the same time, also in constant threatened by all kinds of emergencies.

Decision support system (DSS), is a intelligence function with the management science, operational research, cybernetics and behavior science as the foundation, with computer technology, emulation technology and information technology as the means, in view of the semi-structured Decision problem, and support the decision-making activities of the human-machine system. Able to provide the required data, information and background information, help clear decision goal and to identify problems, and to establish or modify the decision model, offers a variety of alternative, and to evaluate various options and optimization, through the human-computer interaction function analysis, comparison and judgment, provide necessary support for the correct decision [1, 2]. Although preliminary established the city emergency management system in China, but in the face of complex urban emergency, the existing emergency management system is difficult to effectively cope with. The government should be how to the most effective way to control the influence of the incident and spread, quickly return to normal state, is a difficult problem to be solved. Decision support system provides a new method to solve such questions and ideas. 


\section{Structure on Decision Support System}

Decision support system in general consists of the interaction of language system, system and database, model base, method base, knowledge base management system. In some specific decision support system, also can not separate the knowledge base and its management system, model base and method of library usually is a must. Caused by the applications and research methods, the structure of decision support system has a variety of forms. The general decision support system structure is shown in Fig. 1.

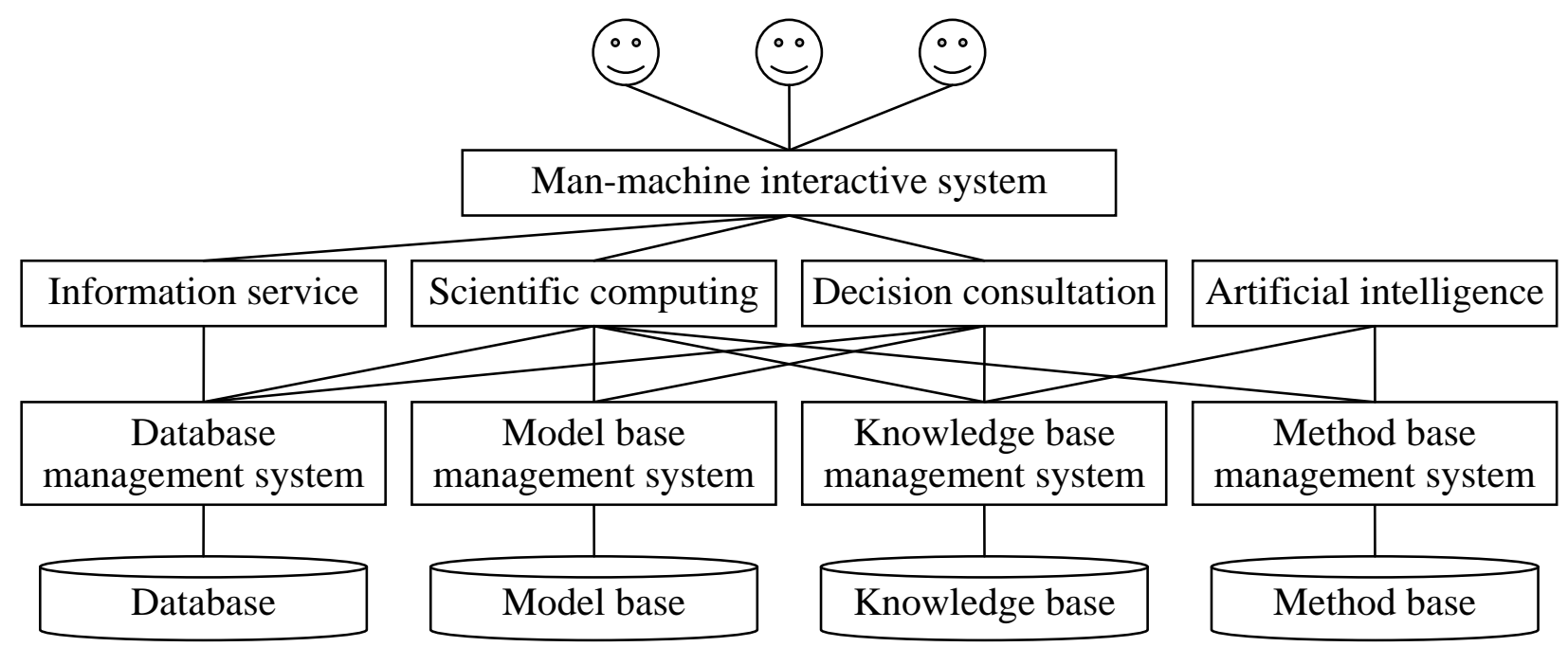

Fig. 1. Structure of decision support system

(1) Human-computer interaction system. The human-computer interaction system with the birth of the computer is developed. In modern and future society, as long as the use of communications, computer information processing technology, such as for the social, economic, environmental and resource activities, human-computer interaction is an eternal theme. In view of its importance to the development of science and technology, the research of how to realize the natural, convenient and ubiquitous human-computer interaction, as a modern information technology, artificial intelligence technology research to aim high, and mathematics, information science, intelligence science, neuroscience, and physiological, psychological science more science, cross new combining site, and will lead the 21st century early popular direction of information and computer studies. The human-computer interaction system is a decision support system for human-computer interaction interface, used to receive and test the user requests, call system internal software for decision service function, make the model run, data calls and knowledge reasoning to organically unify, effectively solve the decision problem.

(2) Four kinds of functions: The first is information service, it can also be divided into external and internal services two categories. External services mainly refers to provide the information what they need for decision-makers, also can be used as information resources of other systems; internal services is to provide basic data for the realization of other functions. The second is scientific computing, scientific computing is not the optimized calculation of OR, is also not the software package of other model calculations, but refers to conduct necessary calculate when support decision, this computing model does not pursuit complexity, but attention to user involvement and choice. The third is decision consultation, on the basis of scientific computing, after to increase knowledge and reasoning capabilities, it can further play support role in the decision. In order to strengthen the decision advisory functions, sometimes can develop a quasi-expert system for DSS. The fourth is artificial intelligence, support functions with artificial intelligence is the best DSS, it pursue the goal is mainly to fully interact with humans and machines, to achieve the purpose of working together to complete the decision tasks. DSS with intelligent can consider reaching the highest support level. 
(3) Four kinds of management system: The first is database management system, is a basic component of DSS for the establishing, using and maintaining the database, the database unified management and control to ensure the security and integrity of the database. The second is model base management system, the main functions are: To provide users with characteristic information about the model attribute, to guide user to quickly and accurately find relevant models, to provide relevant information to the user to add the source code of model and execute code modify and model changes. The third is method base management system, Methods base management system (MBS) is primarily a software system, together with the programs and data, a new generation of MBS should have a scalable application components, new components can be added at any time, can be connected to multiple databases, and apply relational control system. The fourth is knowledge base management system, when the DSS direct to intelligent to develop, the research of knowledge and reasoning become increasingly important. When developing the knowledge base should consider the following issues: for natural language understanding to create semantic and pragmatic environment, for modeling and numerical calculation to provide the necessary analysis basis, add and extend the thinking skills of decision-makers.

\section{Function on Decision Support System}

Software function is a software should have the efficiency and effect, software goal through software functions to express and implementation, software function and software is presented to the user directly effect. User through software provides functions to understand, use and evaluation system, through the use of the software functions to complete the operation. Functional requirements is the most important content requirements analysis. Functional analysis is based on software, form with the results of the model of the software functions, and quantitative or qualitative description of the functions of the software is put forward. Urban emergency government emergency decision support system of common functions as shown in Fig. 2 [3-7].

\begin{tabular}{|c|c|}
\hline Decision Support System on Government Emergency Management for Urban Emergency \\
\hline Model management system & Information feedback system \\
\hline Knowledge management system & Assistant decision system \\
\hline Method management system & Urban information system \\
\hline Comprehensive management system & \\
\hline Office support system & Consequence evaluation system \\
\hline Information exchange system & Comprehensive coordination system \\
\hline Safety protection system & Disposal evaluation system \\
\hline Emergency warning system & \\
\hline
\end{tabular}

Fig. 2. Function of decision support system on government emergency management for urban emergency

Part of the function is shown in Fig. 2 are briefly described as follows:

(1) Integrated management system. It's mainly responsible for processing auxiliary emergency management department of emergency management in daily business, including receiving information, information report and daily work management, system functions include emergency information and related data query, the summary according to the business process of the collected information, analysis, processing, forming information letters, phone records, reported on duty list etc.

(2) Office support system. Will be complicated, streamline business process automation and digitalization, improve the work efficiency of emergency management. Users according to need to 
be flexible customization process and interface style. Have a combination of the background management functions, such as storage management, classification management, views management, custom attributes and the user management, etc. Through the application of the background management system, according to the actual situation and work needs, complete the business view, information form, operation process and personnel access content customization.

(3) Information exchange system. By using the exchange of information sharing platform, unified the emergency command system of different departments together effectively, not only can achieve heterogeneous systems interconnection, can also solve the real-time large capacity of data exchange between each system, secure transmission, such as licensing and regulation of business problems. Information exchange system using message-oriented middleware products, provide the data format conversion, data filtering, data compression, data encryption, and exception handling, and other functions.

(4) Security protection system. From the aspects of technology, management and staff, an effective safety protection ability, hidden dangers found ability and emergency response ability, for the city emergency command system to establish a reliable safe operation of the environment, to ensure the safety of emergency rescue command scheduling system. Related to physical security, network security, system security, application security and security management, etc.

(5) Information feedback system. Will reflect system operation and effect to the system itself, the main work is to investigate every system operation condition of the internal mechanism and working effect, and give reasonable and fair evaluation, and then pass to assess a corresponding mechanism, in order to check, perfect the mechanism construction, improve the work style, eventually achieve the goal of optimization system is running.

(6) Auxiliary decision system, with decisions the theme as the center of gravity, by Internet search technology, intelligent information processing technology, and natural language processing technology as the foundation, to build decision subject research related knowledge base, policy analysis model library and intelligence research method library, building and perfecting the auxiliary decision system, provides the omni-directional and multi-level decision support for the decision-making themes and knowledge service. Provide decision basis for industry research institutions and government departments, help, help, and the purpose of the auxiliary decision makers.

\section{Technology on Case Based Reasoning}

Case -based reasoning (CBR) is by looking for similar Case history, the use of experience or the results of specific knowledge that is specific Case to solve the new problems. CBR is a new rise in the area of artificial intelligence is an important problem solving, and learning method based on knowledge, solve the problem through the reuse or modify the solution to the problem of similar before. CBR research methods derived from human cognitive psychological activity, alleviate the conventional knowledge acquisition bottleneck problems in knowledge system, combining quantitative analysis with qualitative analysis, has the characteristics of the dynamic knowledge base and incremental learning.

Case-based reasoning is derived from a common way to solve the problem of human, the human can use previous experience and knowledge to solve the existing problems. So, case-based reasoning is established based on the following two assumptions: one is that the same or similar problems have the same or similar solution; The second is, things will repeat the same or similar. Principle of case-based reasoning is a traditional Watson methodology, reasoning methods, using case-based reasoning the solution of the problem doesn't need to know, you just need to collect the past the same or similar example, and does not require complete domain knowledge. Using case-based reasoning, must have the following steps: one is to retrieve, from a historical case retrieval and the current problems in case the most similar case; Second, matching, using the solution to deal with the current problem of similar cases, is the goal of case-based reasoning; Three is to adjust, if the solution is not completely in line with the current problems of historical cases, need to adjust the solution of case history, the correct solution to the problem; Four is the study, the 
revised case saved to the database in a new case, for later use reasoning. Case-based reasoning process is shown in Fig. 3.

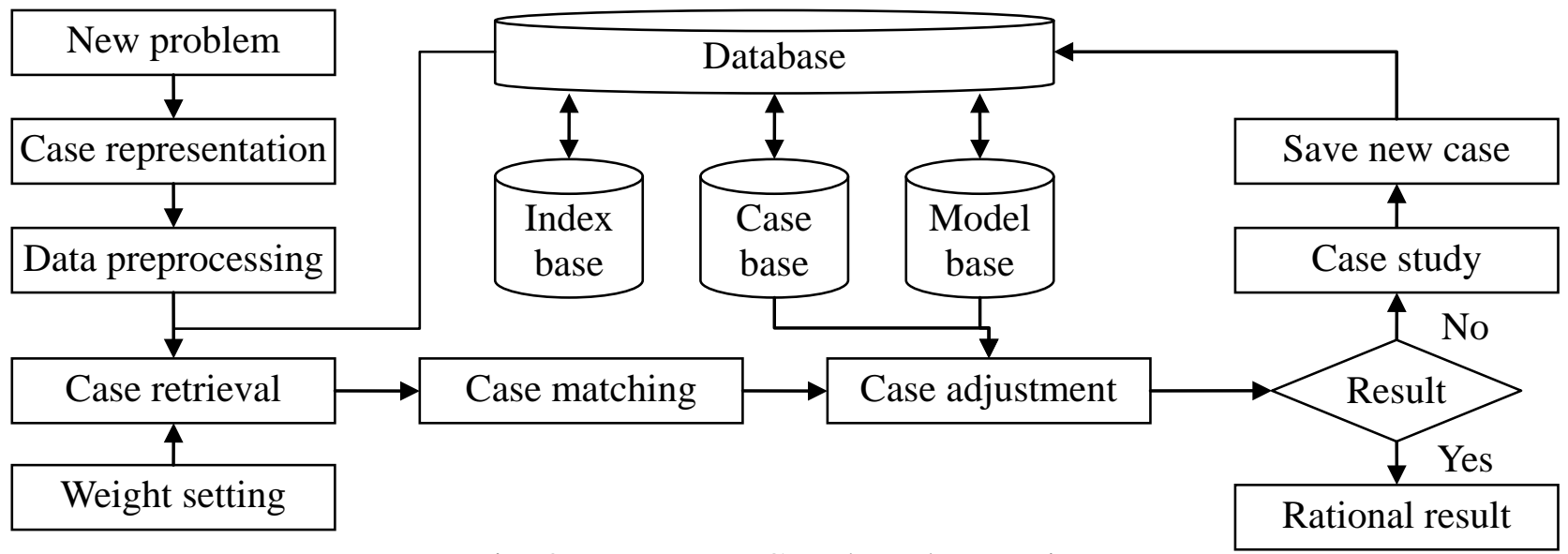

Fig. 3. Process on Case based reasoning

Urban emergency government emergency management of contingency plans using case-based reasoning process as shown in Fig. 4.

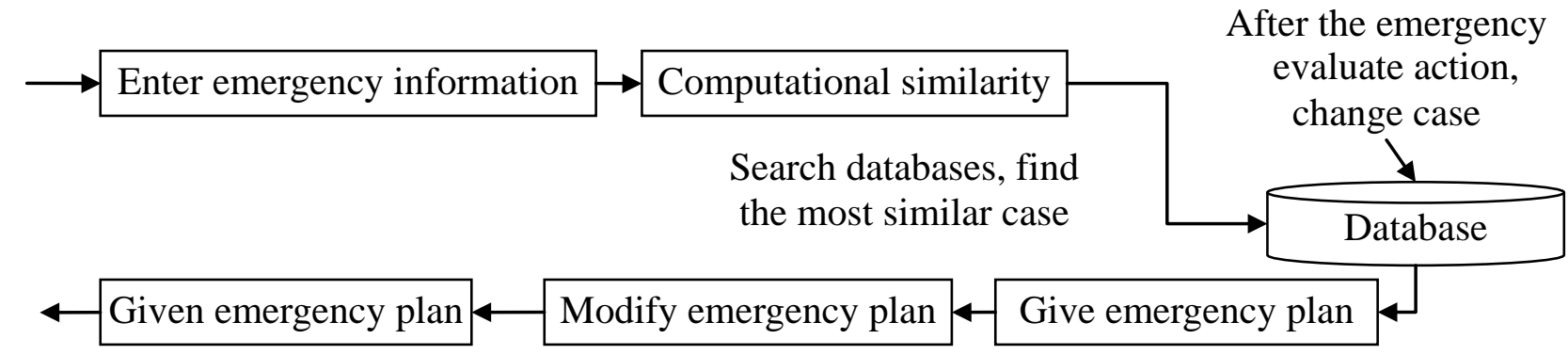

Fig. 4. Emergency case reasoning process

CBR the basic process to solve the problem is: a new problem to be solved, the goal is a case; Using the description of the target case information query similar cases in the past, namely to retrieve putted forward, get similar source case and target case, thus gain some solutions to the problems of new; If the solution plan will adjust its failure, in order to obtain a successful cases can save. After the end of this process, can be a complete solution to obtain the target case; If the source case failed to give a correct solution, by case revision and save can gain a new source of case. In the process of case-based reasoning, case representation, case retrieval and case adjustment is the core issue of case-based reasoning research. Most of the existing system of case-based reasoning is essentially case retrieval and case reuse system, and adjust case is usually the case reasoning system administrator to complete.

\section{Conclusion}

Currently China is in the accelerating period of social transformation and economic transition, all kinds of emergencies in all regions and cities, to a certain extent, affects the normal operation of the economic and social system. Rapid growth in the city at the same time, the new hidden danger and crisis also is in rapid growth, so to reduce the development risk, improve the emergency ability of the city, the city emergency management and emergency rescue become the hot spot in the world, the world had maintained city public security to the new agenda. How to efficient use of limited resources, in a planned way to design a series of prevention and emergency rescue, improve the urban rapid response to sudden events and anti-risk ability, and provide more efficient emergency rescue service for urban residents, just to be the problem to solve faced by city managers. The research achievements of this paper is of great significance for supporting the government emergency management decisions. 


\section{Acknowledgement}

This work is supported by 2014 annual social science planning fund project of Liaoning province (L14DGL043): Improving to countermeasures on urban emergency government emergency management capacity.

\section{References}

[1] E. Bal Beşikçi, O. Arslan, O. Turan, A.I. Ölçer, "An artificial neural network based decision support system for energy efficient ship operations," Computers \& Operations Research, vol. 66, no. 2, pp. 393-401, 2016.

[2] Igor Kabashkin, "Heuristic Based Decision Support System for Choice of Alternative Routes in the Large-Scale Transportation Transit System on the Base of Petri Net Model," Procedia Engineering, vol. 134, pp. 359-364, 2016.

[3] Behnam Malakooti, "Systematic decision process for intelligent decision making," Journal of Intelligent Manufacturing, vol. 121, no. 5, pp. 1342-1355, 2009.

[4] S. Chen, D. Yu, X. Z. Zheng, et al, "Dynamic synergistic emergency decision on major events," China Safety Science Journal, vol. 25, no. 3, pp. 171-176, 2015.

[5] W. Xiong, "Design and implementation of safety emergency management information system," China Management Informationization, vol. 16, no. 7, pp. 59-61, 2013.

[6] X. M. Liu, "Research on Prediction Model of Public Crisis Events and Its Application," Master's degree of Lanzhou University, 2013.

[7] L. He, B. Y. Lu, L. Zhang, "Function analysis and framework construction of urban emergency command system," Jiangsu Science \& Technology Information, vol. 26, no. 11, pp. 29-30, 2009. 